\title{
Higher Education, Youth and Migration in Contexts of Disadvantage: Understanding Aspirations and Capabilities
}

\author{
By Faith Mkwananzi \\ Cham, Switzerland: Palgrave Macmillan, 2019, pp. XXI, 267, ISBN 978-3-030-04452-7.
}

The United Nations High Commissioner for Refugees' Global Trends Report (UNHRC: New York, 2018 , p. 2) found that 70.8 million people have been forcibly displaced worldwide because of "persecution, conflict, violence, or human rights violations". The world has observed substantial growth in the global population of forcibly displaced people over the past ten years. If we look at the South African case, the International Organisation of Migration (IOM) reported that there were more than three million migrants in the Southern African Development Community (SADC) with South Africa being the preferred destination for $58.4 \%$ of SADC migrants seeking employment opportunities (IOM, 2016, Migration in Southern Africa, 12th Regional Meeting of the ACP-EU Joint Parliamentary Assembly, April 20-22, Gaborone, Botswana). South Africa attracts different types of migrants such as professionals, international students and asylum seekers, often seeking economic and political refuge.

Faith Mkwananzi's timely book, Higher Education, Youth and Migration in Contexts of Disadvantage: Understanding Aspirations and Capabilities sets out the complexities and aspirations of youth migration and focuses on the lives of the youth who migrated from Zimbabwe to Johannesburg due to different "push and pull factors" as Mkwananzi explains in her book (38). For many of the young immigrants taking part in Mkwananzi's study, South Africa seems to provide better opportunities than their home countries. In Chapter 1, Mkwananzi first explains the interlink between migration and the Sustainable Development Goals. She then focuses on contextualising migration in the Global South. Young migrants' stories in Chapter 2 provide an insight into young people's daily lives and choices in Johannesburg. It also tells the reader about the challenges facing young people and why they made the decision to leave Zimbabwe. Reading the stories of these young migrants helps the reader to understand their pre- and post-migration experiences, and successfully sets the scene for the rest of the book.

Chapter 3 provides an overview of the Capabilities Approach (CA) and justifies its use for (and contribution to) the study. Mkwananzi emphasises that the CA "provides a base for improved understanding of the links between migration and development" since it is a multidimensional approach that can incorporate the diverse issues of migration and education (69-70). Chapter 4 conceptualises and discusses a four-fold aspirations formulation (resigned, powerful, persistent, and frustrated) from a CA perspective to provide a better understanding of the aspirations formed by the marginalised migrant youth participating in the study. In this Chapter, Mkwananzi also identifies major conversion factors that impact migrant youths' lives and educational aspirations, which involve economic, personal, social, and institutional factors. Categorising these four different conversion factors helps to understand the external and internal influences affecting the migrant youths' aspirations and development.

After conceptualising the CA and examining the major conversation factors, Chapter 5 looks at several capabilities and functionings identified as valuable by the migrant youth interviewed for the study. For instance, education is one of the capabilities the migrant youth find valuable and believe "they would not experience an independent life" without (131). This chapter emphasises the fact that most of the migrant youth place a high value on higher education and believe that it would help them to achieve their long-term aspirations (which appear to differ between men and women, which is important for gender-specific policy and further research considerations, but typically include capabilities relating to family, recognition, and income) (148-157). Chapter 6 sets out to explore the pre-migration educational aspirations and challenges facing the migrant youth. Mkwananzi points out that it is significant to understand the migrant youth's previous experiences to be able to identify how they form their current aspirations. The impact of poverty, the influence of parents and the effect of education (especially if they completed their education in Zimbabwe) were reflected in and contributed to the formation of their 
aspirations. Chapter 7 focuses on the interaction of capabilities and conversion factors that influence the aspirations of the migrant youth. Moreover, this chapter discusses the importance of agency and helps the reader to understand that freedom of agency is crucial for the migrant youth to achieve their desires (217). The last chapter, Chapter 8, provides reflections on the empirical findings, theoretical contributions and policy implications of the study.

Faith Mkwananzi's book is thoughtfully written, well-researched and provides excellent insight into the challenges and aspirations of young migrants entering South Africa. It also provides a deeper understanding of the challenges confronting not only the migrant youth in Johannesburg but migrants around the world.

Ecem Karlıdă̆-Dennis (C) 2020 Institute for Social Innovation and Impact, University of Northampton, UK karlidagecem@gmail.com 